\title{
Resultados preliminares do processamento de dados de sísmica rasa em rochas fraturadas do Grupo Itararé
}

Brunetta, R. ${ }^{* 1}$, Lonardelli, J. N. ${ }^{2}$, Rigoti, A. ${ }^{3}$, Rostirolla, S. P. ${ }^{3}$, Appi, C. J. ${ }^{4}$ Bolsista CAPES - Pós-Graduação em Geologia/UFPR; '²ós-Graduação em Geologia/UFPR; ' 2 Lab. De Análise de Bacias e Petrofísica-Degeol/UFPR; ${ }^{4}$ PETROBRAS/CENPES/PROFEX

Copyright 2004, SBGf - Sociedade Brasileira de Geofísica

Este texto foi preparado para a apresentação no I Simpósio Regional da Sociedade Brasileira de Geofísica, São Paulo, 26-28 de setembro de 2004. Seu conteúdo foi revisado pela Comissão Tecno-científica do I SR-SBGf mas não necessariamente representa a opinião da SBGf ou de seus associados. E proibida a reprodução total ou parcial deste material para propósitos comerciais sem prévia autorização da SBGf.

\section{Resumo}

A sísmica de alta resolução foi aplicada em estudos de rochas do Grupo Itararé para a caracterização de reservatórios fraturados. A área em estudo localiza-se próxima a cidade de Ponta Grossa (PR), onde há uma porção aflorante de arenitos, folhelhos, diamictitos e conglomerados basais. O processamento sísmico das linhas adquiridas tem se tornado um grande desafio por ser difícil a identificação de bons refletores no domínio do tiro. Na tentativa de se identificar estes refletores, técnicas consagradas no processamento sísmico tradicional, como a Deconvolução Preditiva e a Migração, vem sendo utilizadas com relativo sucesso na área em estudo, mesmo sendo questionáveis sua utilização no processamento sísmico de alta resolução.

\section{Introdução}

O método sísmico de reflexão é ferramenta indispensável na exploração de petróleo. Investiga quilômetros de profundidade, tanto em mar como em terra. Associa-se a outros métodos exploratórios para determinar as situações mais favoráveis à ocorrência de hidrocarbonetos, orientando a locação de furos de sondagem. Numa fase mais avançada da exploração, métodos sísmicos executados em furos de sondagem auxiliam na análise de reservatórios, otimizando a explotação. Estas são aplicações consagradas para os métodos sísmicos. Contudo, aplicações da sísmica de reflexão na engenharia e em outras áreas, para investigação rasa que busca alta resolução, é um novo desafio que o projeto Modelagem de Potenciais Reservatórios Fraturados em Superfície para Auxílio Exploratório em Subsuperfície (MODRES) decidiu enfrentar. A aplicação da sísmica de reflexão para investigação rasa só é possível atualmente porque o custo da instrumentação e software necessários caiu para patamares mais aceitáveis.

Dentro do contexto do projeto (MODRES), o método sísmico foi utilizado para auxiliar o mapeamento geológico-estrutural na determinação da geometria da situação análoga, para fornecer subsídios à exploração de alvos profundos. Os dados obtidos são integrados ao conjunto de dados que envolvem os não-sísmicos, geológicos, estruturais e petrofísicos para a modelagem do reservatório.

A área estudada é composta por arenitos e conglomerados basais, sobrepostos discordantemente a folhelhos marrom-chocolate, ritmitos e diamectitos.
Há ainda um controle estrutural formado por um sistema de fraturas conjugadas, dispostas preferencialmente segundo as direções N10-20E e N60-80W.

A instrumentação utilizada na aquisição dos dados consistia de sismógrafos modulares com conversor A/D de 24 bits. Como fontes sísmicas, o projeto utilizou o rifle sísmico calibre 12 e a queda de peso acelerada. A técnica de levantamento foi a do CMP, com arranjo tipo push end-on roll along, com até 96 canais ativos espaçados entre si de 2 metros e tiros a cada 4 metros. Para processamento sísmico o projeto dispõe de softwares considerados "leves".

\section{Processamento de dados sísmicos}

As linhas sísmicas foram planejadas de acordo com as estruturas geológicas mapeadas. A Figura 1 mostra a disposição destas linhas. Antes de se efetuar 0 levantamento sísmico de reflexão, alguns testes foram realizados; entre eles o método de refração, análise de ruído e sismograma sintético.

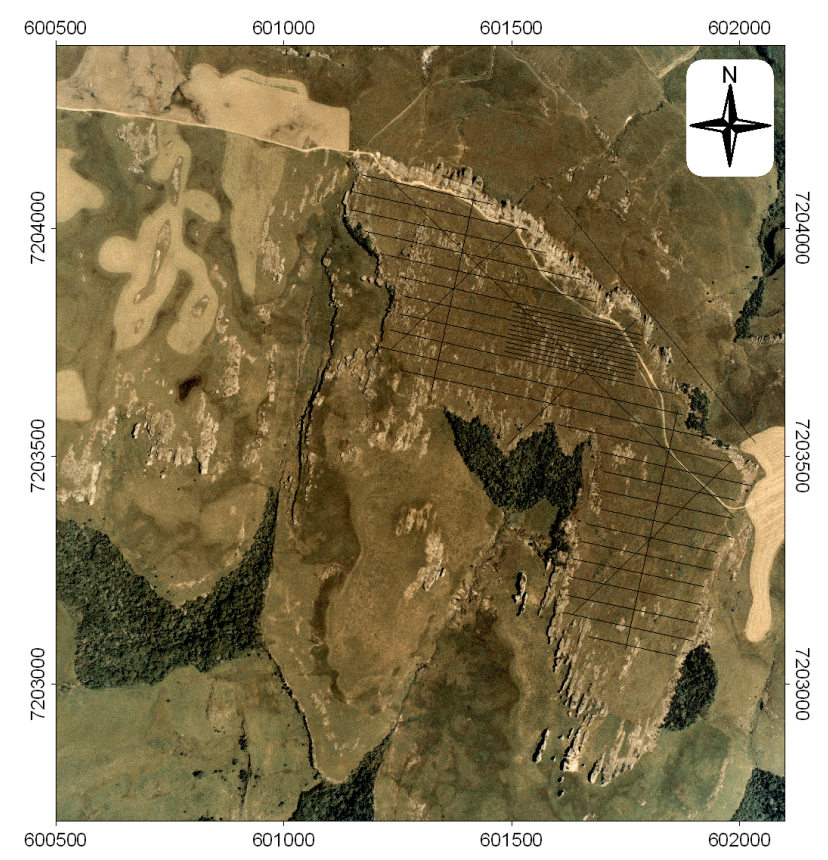

Figura 1 -Planejamento das linhas sísmicas na área de estudo.

Os levantamentos foram divididos em etapas, sendo a primeira delas um pequeno conjunto de linhas para se testar os parâmetros de aquisição e desenvolver as técnicas de levantamento. Isto possibilitava o processamento destas linhas para se avaliar a qualidade dos dados. Não foram evidenciados bons 
refletores até a profundidade interesse ( 100 metros). Sendo assim, o processamento sísmico passou por exaustivos testes. O resultado disso foi um bom aprendizado nas técnicas de processamento atualmente utilizadas. Segundo Baker (1999), o processamento sísmico de alta resolução deve ser simples e os refletores devem ser identificados no dado bruto.

\section{Resultados}

Foram adquiridos aproximadamente 15000 metros de linhas sísmicas, totalizando mais de 4000 tiros. Todo o trabalho de campo levou cerca de cinco meses para ser realizado.

O processamento foi desenvolvido ao longo de toda a campanha sísmica, sendo realizado diversas tentativas para aumentar a razão sinal/ruído. Uma análise preliminar dos dados brutos mostra que há muita reverberação de refração e onda direta, que dificultam a visualização de possíveis refletores, conforme ilustrado na Figura 2.
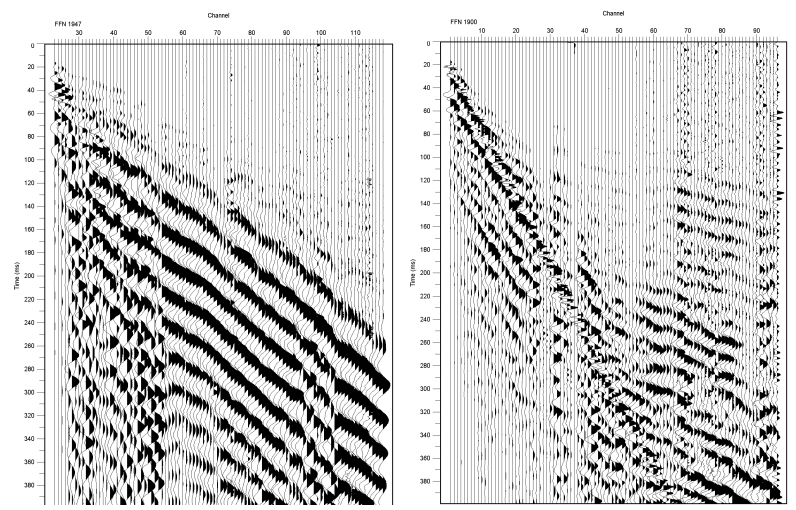

Figura 2: exemplos de dados brutos mostrando intensa reverberação da onda direta e refração.

Uma análise do espectro de freqüências mostra que é muito baixa a amplitude do espectro para freqüências acima de $200 \mathrm{~Hz}$, e que grande parte dos traços encontram-se agrupados em uma pequena faixa de freqüências, conforme exibido na Figura 3. Aplicandose um filtro passa-banda com freqüências de corte de $40 \mathrm{~Hz}$ e $350 \mathrm{~Hz}$, o dado bruto não apresenta nenhuma evidência de refletores.

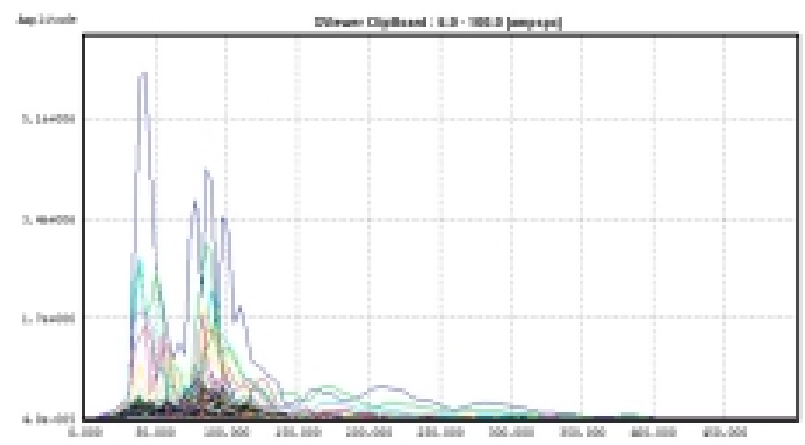

Figura 3: espectro de freqüências obtido durante os levantamentos de reflexão.

Inicialmente tentou-se utilizar o filtro FK, mas sem resultados satisfatórios. A única solução possível seria aplicar um filtro capaz de remover esta reverberação. Verificou-se que a deconvolução preditiva ou filtro Wiener-Levingson apresenta boa performance para esta tarefa. A Figura 4 mostra o resultado da aplicação da deconvolução com sucesso. Mesmo com a aplicação deste filtro, não é possível observar nenhum refletor marcante.

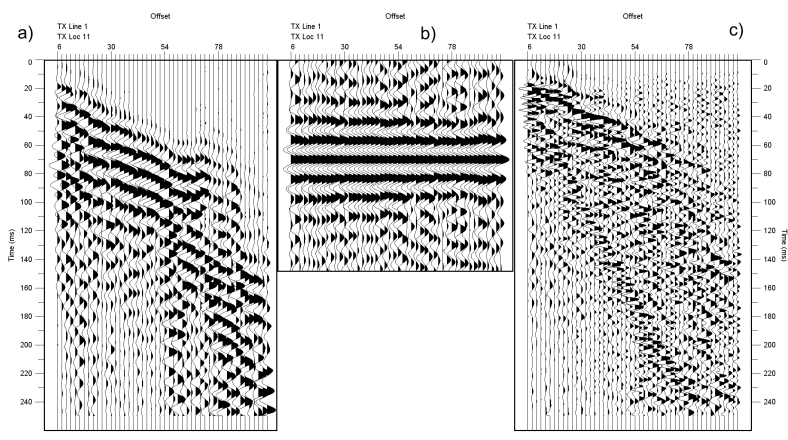

Figura 4: aplicação da deconvolução. a) dado bruto; b) Autocorrelação; c) dado deconvolvido.

A deconvolução, tanto a preditiva quanto a de spiking, é uma ferramenta muito utilizada nos processamentos sísmicos da indústria do petróleo, porém a sua utilização na sísmica de reflexão rasa ainda é muito questionável.

Sendo assim, com a falta de um bom refletor, a análise de velocidade fica muito difícil de se realizar. A técnica utilizada é a geração do painel CVS. A Figura 5 mostra o procedimento para a determinação da curva de velocidade.

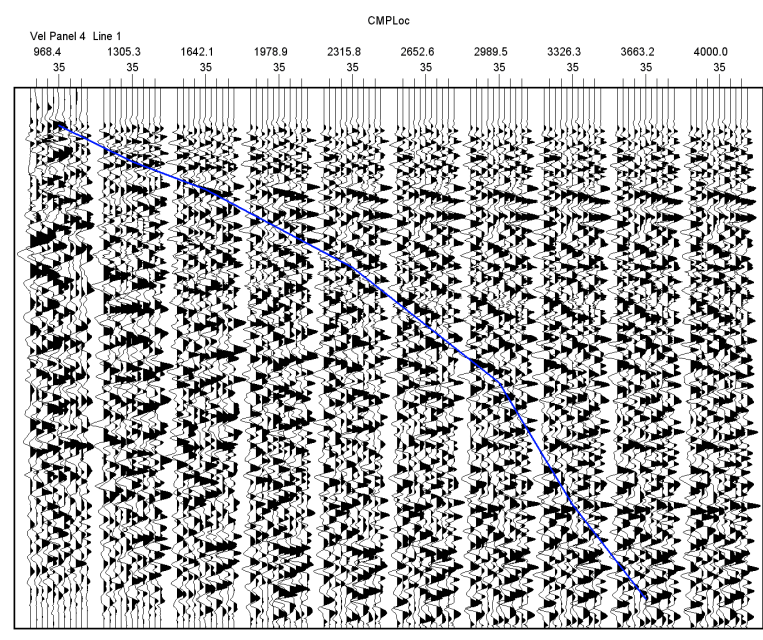

Figura 5: utilização do painel CVS para a determinação da curva de velocidade.

Além destas técnicas, foi aplicada a correção estática por elevação. Apesar de a área apresentar pequenas variações topográficas, acredita-se que este processo seja válido, mesmo se tratando de sísmica de alta resolução.

Tentou-se também a aplicação de migração nas seções sísmicas, mas sem grandes resultados. A técnica utilizada foi a Finite Diference Migration, que aparentemente resolvia alguns problemas de inclinação de camadas, que a geologia descreve como sendo corpos lenticulares. A técnica de Dip Move Out (DMO) resolve estes problemas de inclinação, como pode ser observado na Figura 6.

\section{Discussão e Conclusões}

Apesar da ausência de um bom refletor, as seções finais mostram alguma estruturação coerentes entre si, visíveis em modelos tridimensionais. Se comparada aos modelos geológicos da área, podem-se observar feições lenticulares nas seções sísmicas até aproximadamente $100 \mathrm{~ms}$ ou 100 metros. Abaixo deste 
Brunetta, R., Lonardelli, J. N., Rigoti, A., Rostirolla, S. P., Appi, C. J.

tempo as camadas se tornam mais horizontais, corroborando com os perfis geológicos da área. Alguns poços perfilados mostram uma variação faciológica, porém o perfil sônico não evidencia grandes contrastes de impedância entre essas variações. Segundo estes dados, as velocidades das camadas variam em média entre $2700 \mathrm{~m} / \mathrm{s}$ a $3300 \mathrm{~m} / \mathrm{s}$. Este foi um dos motivos que levaram um refinamento cada vez maior no processamento, apesar da sugestão de Baker (1999) para que se utilize o processamento mais simples possível na sísmica rasa.

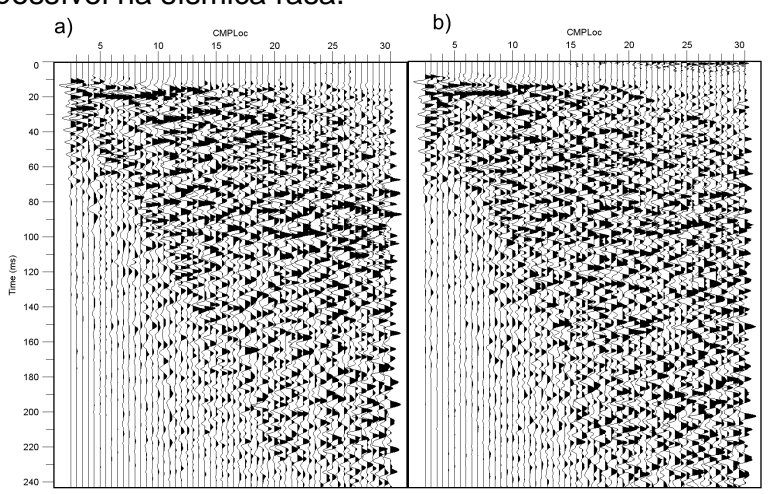

Figura 6: aplicação da correção DMO. a) dado sem correção; b) dado corrigido. Note também que há uma certa extinção da onda aérea.

O fluxograma até então empregado tem muitas semelhanças com um fluxograma empregado tradicionalmente na indústria do petróleo, o que nos leva a crer que as técnicas são perfeitamente aplicáveis à sísmica de reflexão rasa de alta resolução. A experiência com problemas e dificuldades que ocorreram durante o projeto é sempre que, antes de se planejar uma campanha sísmica de reflexão, sejam realizados testes para assegurar que a área escolhida tenha uma boa resposta sísmica.

\section{Agradecimentos}

Os autores

agradecem a CTPETRO/FINEP/PETROBRAS pelo financiamento, a UFPR pelo apoio institucional, ao CNPq pelas bolsas de pesquisa.

\section{Referências (Arial Bold, 9) Veja normas da RBGf}

Baker, G S. Processing near-surface seismic-reflection data: a primer. 1999. Course Notes $n^{\circ} 9$. Tulsa: Society of Exploration Geophysics. 75p.

Bartoszeck, M. K.; Kraft, R. P.; Rostirolla, S. P.; Campos, A. F.; Appi, C. J. 2003. Integração de dados geofísicos e geológicos como ferramenta auxiliar na modelagem de reservatórios em superfície. $8^{\circ}$ Congresso Internacional da Sociedade Brasileira de Geofísica, Rio de Janeiro.

Hunter, J. A.; Pullan, S. E.; Burns, R. A.; Gagne, R. M.; Good, R. S. 1984. Shallow seismic reflection mapping of the overburden-bedrock interface with the engineering seismograph - some techniques. Geophysics, 49: 1381-1385.

Lonardelli, J. N. do; Rigoti, A.; Rostirolla, S. P.; Appi, C. J.; Brunetta, R. 2003. Ensaios sísmicos de reflexão rasa em rochas fraturadas do Grupo Itararé. $8^{\circ}$
Congresso Internacional da Sociedade Brasileira de Geofísica, Rio de Janeiro.

Mayne, W. H. 1962. Common reflection point horizontal data stacking techniques. Geophysics, 27, 6: 927-938.

Yilmaz, O. 2000. Seismic Data Processing - Vol1. Tulsa: Editor Stephen M. Doherty. 1000p. 
